\title{
ОБЩАЯ ПЕДАГОГИКА
}

УДК 373.1174

DOI: $10.26456 /$ vtpsyped/2021.3.092

\section{ЦИФРОВАЯ ОБРАЗОВАТЕЛЬНАЯ МАСТЕРСКАЯ КАК ФУНКЦИОНАЛЬНО-СОДЕРЖАТЕЛЬНАЯ МОДЕЛЬ СОВРЕМЕННОГО ОБРАЗОВАНИЯ*}

\author{
И.Д. Лельчицкий ${ }^{1}$, А.П. Сильченко ${ }^{1}$, \\ С.Ю. Щербакова ${ }^{1}$, Н.А. Баранова ${ }^{2}$
}

${ }^{1}$ ФГБОУ ВО «Тверской государственный университет», Тверь

${ }^{2}$ ГБПОУ «Тверской колледж культуры имени Н.А. Львова», Тверь

Обоснован педагогический феномен «цифровая образовательная мастерская». Предложена типология цифровых образовательных мастерских и технология их реализации, установлены функции и представлено содержание различных типов цифровых образовательных мастерских. Сформулированы цифровые компетенции педагога как участника и модератора цифровой образовательной мастерской.

Ключевые слова: ичирровая трансформация образования, изифровая образовательная среда, иифровая образовательная мастерская, циирровая педагогическая мастерская, ичифровые компетенции педагога, цифровая духовно-нравственная мастерская, цифровая учебная мастерская, иифровая академическая мастерская.

В федеральных проектах «Цифровая образовательная среда», «Современная школа», реализуемых в рамках национального проекта «Образование» (2019-2024) обозначены стратегии развития современного образовательного пространства, отвечающие вызовам переживаемой действительности, среди которых наиболее рельефно проявляет себя феномен цифровизации, объективно воспринимаемый сегодня как один из ключевых критериев организационносодержательного устройства современного образовательного пространства. Охарактеризованный вызов сфере образования детерминирует разработку новых технологий, создаваемых посредством использования цифровых инструментов, непременно сопровождаемый обоснованием соответствующего контента, обеспечивающих прежде всего интерактивный, максимально творческий процесс образования. Осуществленный анализ публикаций, посвященных педагогическим технологиям, рефлексия педагогической практики авторов настоящей статьи позволяет выдвинуть идею и предложить технологию реализации

\footnotetext{
* Работа выполнена в рамках проекта РФФИ № 20-013-00150\21 «Теоретикометодологическое обоснование и технология разработки цифрового образовательного контента в образовательной организации», 2020-2021 г.

(с) Лельчицкий И.Д., Сильченко А.П., Щербакова С.Ю., 
цифровой педагогической мастерской с обоснованием ее типологии в контексте стратегических приоритетов развития отечественного образования.

Прежде чем обосновывать феномен цифровой образовательной мастерской, представляется логичным остановиться на близком, но тождественном феномене, который в образовательной практике и теории трактуется как педагогическая мастерская. Так, в диссертационных исследованиях, посвященных теоретическому обоснованию и эмпирической проверке эффективности педагогической мастерской, она рассматривается в качестве средства развития личности участников образовательной деятельности (Н.И. Белова, 2000) или понимается как инновационный подход $к$ совершенствованию профессионализма учителя (Т.Ю. Макаренкова, 2009). В ряде статей и учебных пособий педагогическая мастерская определяется как средство подготовки будущих специалистов к профессиональной деятельности (Г.Я. Гревцева, 2012) либо как современная инновационная педагогическая технология (Г.К. Селевко, 1998) и др.

Принципиальной представляется позиция исследователей, согласно которой педагогическая мастерская рассматривается как «средство активизации познавательного интереса школьников». Наличие педагогической мастерской становится условием «для восхождения каждого участника к новому знанию и новому опыту путем самостоятельного или коллективного открытия. Основой открытия в любой сфере знаний, включая самопознание, в мастерской является творческая деятельность каждого и осознание закономерностей этой деятельности» [2, с. 209-210].

По существу, все авторы, акцентируя внимания на различных аспектах предназначения педагогических мастерских, подчеркивают интерактивную, осуществляемую с достаточной степенью творчества учебно-познавательную деятельность, отличительной особенностью которой является организация и поддержка со стороны педагога ее рефлексивного характера, что призвано обеспечивать формирование у обучающихся готовности к известной степени самостоятельности в овладении новым знанием, минимизации репродуктивного начала в построении образовательного процесса. Следовательно, в имеющихся научных исследованиях «педагогическая мастерская» представлена как педагогическая технология достижения различных видов опыта.

Отвечая на современные вызовы в сфере образования, нам представляется обоснованным обращение к феномену «цифровая образовательная мастерская», являющему собой систему цифровых сервисов, содержание которых адресовано для различных участников образовательной деятельности с целью педагогического обеспечения субъектной позиции каждого из них. Необходимо подчеркнуть, что цифровая образовательная мастерская включает в себя различные по 
ценностно-целевому предназначению типы цифровых мастерских. Так, например, цифровая учебная мастерская направлена на развитие познавательного интереса обучающихся различных возрастов, имеет свой маркетплейс образовательного контента, различные тренажеры и симуляторы, основанные на ситуационной модели реализации культурологического подхода, что представляется значимым для развития различных видов опыта и навыков [4].

Следовательно, цифровая образовательная мастерская представляется одним из ключевых вариантов организационносодержательного устройства цифровой образовательной среды. На рисунке №1 представлен пример типологии цифровых образовательных мастерских, ядром которых выступает целостная цифровая педагогическая платформа с единой точкой доступа.

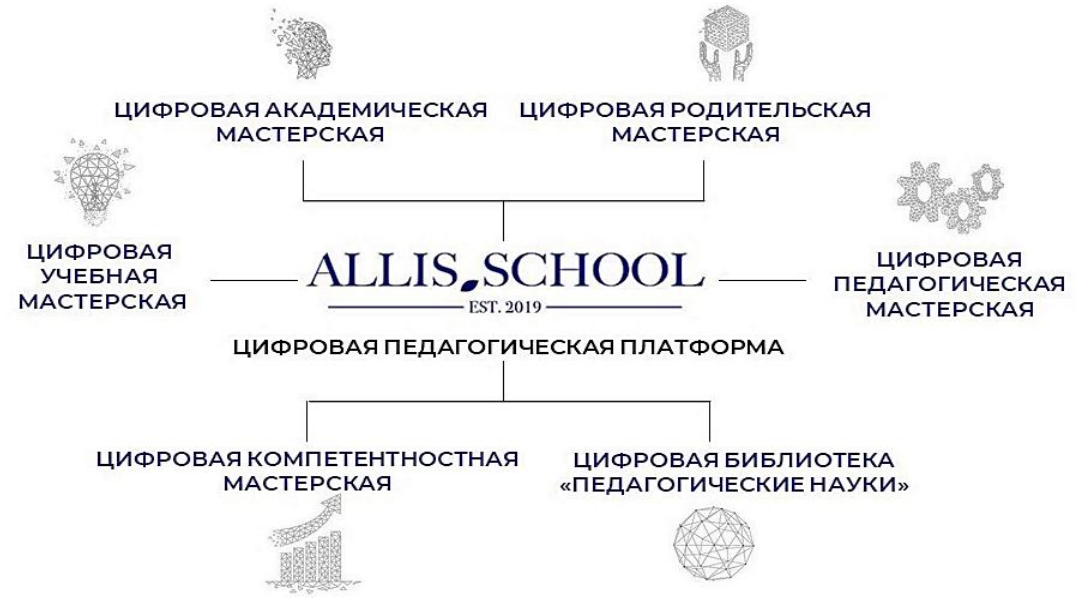

Рис. 1. Типология цифровых образовательных мастерских

Это первичная номенклатура цифровых образовательных мастерских, она может масштабироваться и изменяться. Например, организация цифровой психолого-педагогической мастерской, в которой, очевидно, будет реализован диагностический комплекс, маркетплейс образовательного контента для психологов-диагностов, цифровой профессиональный инструментарий психолога и т.д.

В серии предыдущих статей авторами были сформулированы принципы, разработаны теоретические основы проектирования структуры цифровой образовательной среды, построена еe функционально-дидактическая схема $[1 ; 5 ; 6 ; 8]$. Например, основу проектирования цифровой образовательной среды в образовательной организации определили два основных принципах - принцип объективизации и принцип стандартизации, условием осуществления которых является стандартизация профессиональной деятельности учителя с сохранением и даже усилением его творческого начала [8]. Традиционные этапы профессиональной деятельности учителя, 
представленные на рис. 2, в предлагаемой цифровой образовательной среде наполняются новыми смыслами и обеспечиваются новыми цифровыми компетенциями [1; 5]. Проведенный анализ литературы свидетельствует о существовании различных подходов и различных моделей цифровых компетенций педагога.

Так, в европейской рамке компетенций учителя (Digital Competence of Educators - DIGCOMPEDU) представлены следующие 3 блока уровней цифровых компетенций педагога: цифровые профессиональные компетенции, т.е. компетенции, которыми должен обладать любой современный работник; цифровые педагогические компетенции - специфические компетенции, необходимые в педагогической деятельности: использование цифровых образовательных ресурсов, обучение, оценивание и т.п.; цифровые компетенции педагога, направленные на формирование цифровой грамотности обучающихся, т.е. информационной и медиаграмотности, расширение цифрового общения и развитие сотрудничества, создание образовательного цифрового контента и т.п. [3].

Другая модель цифровых компетенций педагога была построена в России на основании опроса 30 тысяч учителей, проведенного инициативной группой цифровых образовательных компаний. Эта модель базируется на следующих 7 группах компетенций: поиск и работа с информацией; безопасность в интернете (кибербезопасность); управление информацией и данными; организация обучения в цифровой среде; кооперация в цифровой среде; коммуникация в цифровой среде; саморазвитие в условиях неопределенности [7].

При проектировании цифровой образовательной среды авторами учитывались оба подхода и были выделены следующие группы цифровых компетенций учителя, описанных выше: поиск и работа с информацией и данными; организация обучения в цифровой среде; организация коммуникации в цифровой среде; организация кооперации в цифровой среде. Содержание деятельности учителя на каждом из указанных выше этапов (рис. 2) учтено авторами при конструировании базовой структуры цифровой образовательной среды. Необходимые цифровые компетенции педагога будут формироваться через систему цифровых педагогических платформенных решений, то есть интеграцию разных сервисов и образовательных продуктов в единую экосистему, предполагающую разнообразие участников, человекоцентрированность, сотрудничество и синергию [1].

ЦИФРОВАЯ ОБРАЗОВАТЕЛЬНАЯ СРЕДА

ПРОЕКТИРОВАНИЕ РЕАЛИЗАЦИЯ АНАЛИЗ ИССЛЕДОВАНИЕ

Рис. 2 Этапы профессиональной деятельности учителя 
На этапах «Проектирование» и «Реализация» учителю удобно пользоваться цифровой учебной мастерской, которая представляет собой сервис как синхронного, так и асинхронного on-line обучения школьников по ключевым предметам и ориентирована на метакомпетентное развитие обучающихся. В ней успешно могут быть реализованы такие аспекты концепции гибкого обучения как: обучение в любом месте и в любое время; обучение через социальные сети и медиа; интерактивность обучения; коллаборация обучения.

Функционирование системы цифровых мастерских позволяет на основе анализа личной образовательной траектории персонализировать знания в том формате и объеме, которые необходимы ученику.

Далее, цифровая педагогическая мастерская - это сервис повышения квалификации и переподготовки педагогических и управленческих работников в аспекте формирования необходимых цифровых компетенций и повышения уровня их цифровой грамотности.

Предлагаемая цифровая педагогическая мастерская реализуется по модели WBL (Work-based learning - обучение на рабочем месте, обучение без отрыва от работы) на основе асинхронной кредитномодульной системы конструирования индивидуальной практикоориентированной образовательной траектории и ориентирована на цифровые технологии, востребованные на рынке труда.

В связи с этим большое значение придается проблеме формирования цифровых компетенций педагога, так как именно это формирует его готовность к продуктивному использованию цифровых мастерских в своей профессиональной деятельности.

Во-первых, при формировании компетенции поиска и работы с информацией и данными обращается внимание на этику и безопасность работы с данными, использование инструментов обезличивания данных при необходимости, на то, что данные носят объективный характер, а информация приобретает субъективность в результате обработки данных. Понимание роли и места информации в обучении, скорость ее обновления обеспечивается критическим отношением к eе достоверности. Здесь учителя (преподаватели) осваивают цифровые инструменты обработки и хранения информации, в частности учебной аналитики и ее видов (описательная, дескриптивная, предиктивная, прескриптивная), использование цифровых технологий для анализа прогресса и оценивания достижений обучающихся, используют, например, BigData, облачные хранилища Dropbox, ICloud, OneDrive. Владение этой компетенцией необходимо учителю, например, на этапе «Анализ».

Во-вторых, при формировании компетенции организации обучения в цифровой среде следует помнить о вероятности перенесения в цифровую реальность дискриминации, которая может выражаться в 
следующем: в перебоях в работе Интернета, в отсутствии гаджета или в его устаревшей модели, не поддерживающей предлагаемые цифровые ресурсы (например, не все модели телефонов позволяют демонстрировать презентации или строить графики), в качестве веб камеры, микрофона. Эта компетенция важна на этапе «Реализация».

Акцентируется, что визуализация информации для обучающихся должна осуществляться с учетом особенностей поколения центениалов (поколения Z), в частности преобладание у многих из них клипового восприятия, требующего новой и все более яркой информации. С другой стороны, это отвечает одному из основополагающих требований современного рынка образования: «Думай, как маркетолог: упакуй свой продукт красиво».

В-третьих, обязательность социального общения является еще одной особенностью центениалов. В связи с этим, особого внимания требует компетенция педагога «организация коммуникации в цифровой среде». Помимо этого, педагогу необходимо взаимодействовать со всеми участниками образовательного процесса: с обучающимися, с коллегами, с администрацией, с родителями, со всеми, кто оказывается вовлеченным в образовательную деятельность. Коммуникационная компетентность педагога предполагает понимание отличий живого общения от виртуального, умения использовать доступные средства коммуникации, с непременным соблюдением педагогической этики общения.

В-четвертых, компетенция «организация кооперации в цифровой среде» предполагает профессиональное сотрудничество, работу с обучающимися и их родителями с помощью различных цифровых инструментов и технологий.

Цифровая компетентностная мастерская наполнена образовательными тренажерами и бизнес-симуляторами для различных категорий пользователей.

Цифровая академическая мастерская - сервис образовательного контента академической и исследовательской направленности и предполагает уверенное владение компетенциями по поиску и работе с информацией и данными.

Цифровая родительская мастерская представляет собой сервис по педагогической поддержке родителей для развития растущего человека в контексте современных вызовов. При работе в этой мастерской педагогу необходимы сформированные навыки общения в мессенджерах, социальных сетях, чатах, электронной почте, то есть готовность к организации коммуникации в цифровой среде.

Цифровая библиотека по направлению «педагогические науки» база данных научных статей, журналов, тематических видеоматериалов (конференций, семинаров, круглых столов, дискуссий и т.д.) для учителей / преподавателей, студентов, ученых и исследователей в 
области педагогических наук.

Цифровая «игровая образовательная среда» - геймификация учебной и внеучебной деятельности, обеспечивающая активное внедрение игровых приемов в неигровые учебные ситуации, внедрение в образовательную деятельность игровых педагогических технологий. Следует указать на необходимость присутствия всех элементов геймификации: определение мотивов и целей, описание процесса и установление правил, определение игровых механизмов, обеспечение социального взаимодействия (например, указать чат для общения), а также разработку четких критериев оценивания (баллы, временны́е рамки и др.).

Таким образом, в представленной цифровой образовательной среде цифровая компетентность учителя обеспечит ему готовность создавать и применять контент посредством цифровых технологий, технологий виртуальной и дополненной реальности. Вместе с тем, освоение облачных технологий для коллективной работы в цифровой среде непосредственно с обучающимися, их родителями, коллегами будет способствовать повышению качества образования в целом.

Требуют разрешения некоторые существующие проблемы подготовки педагогов для цифровой школы: разрыв между поколениями $\mathrm{X}$ и Z; дефицит педагогических кадров, обладающих необходимым и достаточным уровнем цифровой компетентности для работы в условиях цифровой трансформации образования; несистематическое использование современных педагогических технологий, например, таких как проектная технология, модульная технология, кейстехнология; отсутствие персонализации обучения.

Один из главных вызовов, который предъявляется сегодня педагогическому сообществу, заключается в цифровой грамотности учителя, требующей от него иной ментальности, иных подходов к организации учебной деятельности, иных форм работы с обучающимися.

Охарактеризованные в статье цифровые компетенции учителя, обозначенная необходимость владения ими для успешного функционирования предложенной авторами цифровой образовательной мастерской определяют перспективы для последующих исследований по разработке модели повышения квалификации педагогических работников, их саморазвития и самосовершенствования, их готовности к продуктивному использованию цифровых мастерских в своей профессиональной деятельности.

Предложенная типология цифровых образовательных мастерских позволяет обеспечить для всех участников образовательной деятельности адресно-целевую архитектуру цифровой образовательной среды. Принципиальным условием функционирования модели цифровой образовательной мастерской является ее направленность на обеспечение 
субъектной позиции каждого из ее участников, для которого создаются максимальные возможности, с учетом его индивидуальных запросов, при компетентном педагогическом модерировании, по проектированию и достижению результатов в осуществляемой им деятельности.

\section{Список литературы}

1. Лельчицкий И.Д., Сильченко А.П., Щербакова С.Ю. Теоретические основы проектирования структуры цифровой образовательной среды // Вестник Тверского государственного университета. Серия: Педагогика и психология. 2020. № 3 (52). С. 249-257.

2. Петрова Н.Ф. Педагогические мастерские как средство активизации познавательного интереса школьников // Мир науки, культуры, образования. 2012. № 4 (35). С. 209-210.

3. Редекер К. Европейские рамки цифровой компетентности педагогов: DigCompEdu. Брюссель: Объединенный исследовательский центр Европейского Союза, 2017. URL: https:/ec.europa.eu/jrc/sites/jrcsh/files/ digcompedu_leaflet_en-2017-10-09.pdf (дата обращения: 25.08.2021).

4. Сериков В.В., Сильченко А.П. Модель реализации культурологического подхода при изучении учебного предмета // Вестник Тверского государственного университета. Серия: Педагогика и психология. 2019. № 1 (46). C. 159-166.

5. Сильченко А.П., Лельчицкий И.Д., Щербакова С.Ю., Баранова Н.А., Функционально-дидактическая схема цифровой образовательной среды / Вестник Тверского государственного университета. Серия: Педагогика и психология. 2020. №4(53). С. 111-120.

6. Сильченко А.П., Ситуационная модель реализации культурологического подхода к изучению учебного предмета (на примере информатики в основной и средней школе)/ Отечественная и зарубежная педагогика № 3(60)/2019. С. 121-137.

7. Цифровая грамотность российских педагогов. Готовность к использованию цифровых технологий в учебном процессе. / Т.А. Аймалетдинов, Л.Р. Баймуратова, О.А. Зайцева, Г.Р. Имаева, Л.В. Спиридонова. Аналитический центр НАФИ. М.: Издательство НАФИ, 2019. 84 с.

8. Lelchitsky I.D., A.P. Silchenko, M.V. Tsurkan. Digital Education Environment within the Frame of Schooling: Pedagogic Approaches and Development Strategies/ Proceedings of the 2-nd International Scientific and Practical Conference «Modern Management Trends and the Digital Economy: from Regional Development to Global Economic Growth» (MTDE 2020), Published by Atlantis Press SARL/ 2020, p. 1231-1236.

\section{Об авторах:}

ЛЕЛЬЧИЦКИЙ Игорь Давыдович, - доктор педагогических наук, профессор, академик РАО, директор Института педагогического образования и социальных технологий ФГБОУ ВО «Тверской государственный университет» (170100, Тверь, ул. Желябова, 33), e-mail: Lelchitskiy.ID@tversu.ru 
СИЛЬЧЕНКО Ален Павлович - кандидат педагогических наук, доцент кафедры математического и естественнонаучного образования, заместитель директора по цифровому развитию образовательного процесса Института педагогического образования и социальных технологий, директор Центра научно-методического обеспечения цифрового школьного образования ФГБОУ ВО «Тверской государственный университет», (170100, Тверь, ул. Желябова, 33), e-mail: allentver@gmail.com

ЩЕРБАКОВА Светлана Юрьевна - кандидат физико-математических наук, доцент, заведующая кафедрой математического и естественнонаучного образования ФГБОУ ВО «Тверской государственный университет» (170100, Тверь, ул. Желябова, 33), e-mail: shchsv@ yandex.ru

БАРАНОВА Наталья Александровна - кандидат педагогических наук, доцент, заведующая кафедрой педагогики и психологии ГБП ОУ «Тверской колледж культуры имени Н.А. Львова» (170002, Тверь, пр. Чайковского, 19), еmail: barnat353@yandex.ru

\title{
DIGITAL EDUCATIONAL WORKSHOP AS A FUNCTIONAL- CONTENT MODEL OF MODERN EDUCATION
}

\author{
I.D. Lelchitsky ${ }^{1}$, A.P. Silchenko ${ }^{1}$, \\ S.Yu. Shcherbakova ${ }^{1}$, N.A. Baranova ${ }^{2}$
}

${ }^{1}$ Tver State University, Tver, Russia

${ }^{2}$ College of Culture named after N.A. Lvov, Tver, Russia

The pedagogical phenomenon «digital educational workshop» has been substantiated. The typology of digital educational workshops and the technology of their implementation are proposed, the functions are established and the content of various types of digital educational workshops is presented. The digital competencies of a teacher as a participant and moderator of a digital educational workshop have been formulated.

Keywords: digital transformation of education, digital educational environment, digital educational workshop, digital pedagogical workshop, digital competencies of a teacher, digital spiritual and moral workshop, digital educational workshop, digital academic workshop. 